\title{
Escarificação do solo e sulcadores em semeadora para cultivo de milho em Planossolos
}

\author{
Robson Giacomeli(1), Enio Marchesan(1), Gerson Meneghetti Sarzi Sartori(1), Gabriel Donato(1), \\ Paulo Regis Ferreira da Silva( ${ }^{(2)}$, Douglas Rodrigo Kaiser ${ }^{(3)}$ e Bruno Behenck Aramburu ${ }^{(1)}$
}

\begin{abstract}
(1)Universidade Federal de Santa Maria, Departamento de Fitotecnia, Avenida Roraima, № 1.000, Camobi, CEP 97105-900 Santa Maria, RS, Brasil.E-mail: robsongiacomeli@yahoo.com.br, eniomarchesan@gmail.com, gersonmss@yahoo.com.br, gabriel.donato@hotmail.com, bruno.behenck@gmail.com (2)Universidade Federal do Rio Grande do Sul, Departamento de Plantas de Lavoura, Avenida Bento Gonçalves, no 7.712, CEP 91540-000 Porto Alegre, RS, Brasil. E-mail: paulo.silva@ufrgs.br (3)Universidade Federal da Fronteira Sul, Curso de Agronomia, Rua Jacob Reinaldo Haupenthal, no 1.580, CEP 97900-000 Cerro Largo, RS, Brasil. E-mail: douglasrodrigokaiser@gmail.com
\end{abstract}

Resumo - O objetivo deste trabalho foi avaliar a escarificação mecanizada do solo e diferentes sulcadores, em semeadora, para cultivo de milho em Planossolos. Dois experimentos foram realizados em campo, em dois locais: Santa Maria e Formigueiro, RS. Um delineamento experimental de blocos ao acaso foi utilizado, com quatro repetições e tratamentos de escarificação do solo (ESC) e semeadura direta, com os seguintes sulcadores: haste sulcadora (HS), haste sulcadora e mecanismo de acomodação do sulco (HAS), disco duplo desencontrado (DD) e disco ondulado (DO). Em Santa Maria, foi adicionado o tratamento semeadura em camalhão com haste (CA). Os seguintes parâmetros foram avaliados: densidade, porosidade e macroporosidade do solo; resistência do solo à penetração mecânica (RP); distribuição do sistema radicular; e produtividade de grãos. Em Formigueiro, os tratamentos ESC, HS e HAS resultaram em menor densidade e maior macroporosidade do solo, nas camadas de $0,05-0,10$ e $0,10-0,20 \mathrm{~m}$. A RP foi menor no tratamento ESC e no sulco da HS até $0,15 \mathrm{~m}$, onde as raízes se desenvolveram melhor. A produtividade de grãos de milho em Planossolos é maior quando a semeadura é realizada sobre camalhão, solo escarificado ou semeadura direta, com haste sulcadora na semeadora.

Termos para indexação: Zea mays, camada compactada, camalhão, haste sulcadora, rotação de culturas, semeadura direta.

\section{Deep tillage and furrow opener seeders for corn cropping in Planosols}

Abstract - The objective this work was to evaluate deep tillage and different furrow opener seeders for growing corn in Planosols. Two experiments were carried out in the field, in two different locations: Santa Maria and Formigueiro, in the state of Rio Grande do Sul, Brazil. A randomized complete block experimental design was used, with four replicates, and treatments of deep tillage (DP) and no-till, using different seed-furrow openers: shank (SH); shank plus furrow accommodation mechanism (SHA); double disk (DD); and notched disk (ND). In Santa Maria, the raised-bed treatment using shank was added (RBS). The following parameters were evaluated: soil bulk density, porosity, and macroporosity; soil penetration resistance (RP); root system distribution; and grain yield. In Formigueiro, the DP, SH, and SHA treatments resulted in lower bulk density and higher soil macroporosity in the $0.05-0.10$ and $0,10-0.20-\mathrm{m}$ soil depths. The RP was lower in the DP treatment and in the furrow of the SH treatment until $0.15 \mathrm{~m}$, where roots developed better. Corn grain yield in Planosols is greater when sowing is carried out using raised bed, deep tillage, or no-till using shank in the seeder.

Index terms: Zea mays, soil compaction layer, raised seedbed, shank, crop rotation, no-till.

\section{Introdução}

Na metade sul, do Estado do Rio Grande do Sul, predominam os Planossolos nas planícies aluviais, o que abrange aproximadamente três milhões de hectares (Bamberg et al., 2009) que apresentam horizonte B adensado e praticamente impermeável (Pinto et al., 2004). Nesses solos, as principais culturas agrícolas são o arroz irrigado por inundação, na primavera-verão, e pastagem com azevém no outono-inverno e, em decorrência do monocultivo do arroz, o número de plantas daninhas resistentes ou de difícil controle por herbicidas tem aumentado (Matzenbacher et al., 2013; Schaedler et al., 2013).

A rotação de culturas é uma prática agrícola importante no controle de plantas daninhas, pois 
reduz o banco de sementes delas (Andres et al., 2001). Nesse contexto, a cultura do milho é uma alternativa para ser utilizada em rotação com arroz irrigado, pois, além de auxiliar o controle de plantas daninhas e a quebra do ciclo de doenças e pragas, contribui para a melhoria das propriedades físicas e químicas dos solos cultivados com arroz irrigado (Vernetti Junior et al., 2009). No entanto, o milho apresenta dificuldade de adaptação às condições físicas dos Planossolos, em razão da elevada densidade, aeração deficiente, baixa condutividade hidráulica e capacidade de armazenamento de água (Pinto et al., 2004). Além disso, os preparos sucessivos para a semeadura do arroz irrigado, muitas vezes em condições de elevado conteúdo de água no solo, contribuem para o processo de compactação desses solos (Moraes et al., 2013).

A realização de práticas agrícolas antes e no momento da semeadura pode auxiliar a redução da compactação de parte da camada compactada e a drenagem dos Planossolos cultivados com arroz. Os mecanismos de deposição do fertilizante na semeadora-adubadora - como o disco duplo, o disco ondulado e a haste sulcadora - influenciam diretamente o desenvolvimento da cultura (Drescher et al., 2011; Modolo et al., 2013). A escarificação do solo, antes da semeadura, também pode ser uma alternativa para minimizar o efeito da compactação e diminuir a densidade e a resistência do solo à penetração de raízes (Colet et al., 2009). A semeadura sobre camalhão é outra alternativa que auxilia a drenagem superficial da água e pode viabilizar o desenvolvimento de culturas de sequeiro, em áreas anteriormente cultivadas apenas com a cultura do arroz (Fiorin et al., 2009).

O objetivo deste trabalho foi avaliar a escarificação mecanizada do solo e diferentes sulcadores em semeadora, para cultivo de milho em Planossolos.

\section{Material e Métodos}

Dois experimentos foram realizados em campo, no ano agrícola 2013/2014, na região ecoclimática da Depressão Central, do Estado do Rio Grande do Sul. O clima é caracterizado como subtropical úmido (Cfa), segundo a classificação de Köeppen-Geiger, adaptado por Alvares et al. (2013), sem estação seca definida, e com precipitação média de $1.616 \mathrm{~mm}$ ao ano. Os dados de precipitação pluvial e de temperatura média do ar da safra agrícola de 2013/2014 estão apresentados na Figura 1.

O primeiro experimento foi conduzido no município de Santa Maria, a 29 $43^{\prime} \mathrm{S}, 53^{\circ} 43^{\prime \prime} \mathrm{W}$ e $90 \mathrm{~m}$ de altitude. O solo é classificado como Planossolo Háplico eutrófico arênico, pertencente à unidade de mapeamento Vacacaí (Santos et al., 2013), com 0,4 $\mathrm{m}$ de horizonte A, e com as seguintes características químicas e físicas na camada de $0,0-0,20 \mathrm{~m}: \mathrm{pH}\left(\mathrm{H}_{2} \mathrm{O} 1: 1\right), 5,3$; saturação por bases, 62,7\%; Al, 0,3 $\mathrm{cmol}_{\mathrm{c}} \mathrm{dm}^{-3}$; Ca, 5,0 $\mathrm{cmol}_{\mathrm{c}} \mathrm{dm}^{-3}$; $\mathrm{Mg}, 2,3 \mathrm{cmol}_{\mathrm{c}} \mathrm{dm}^{-3} ; \mathrm{K}, 60,0 \mathrm{cmol}_{\mathrm{c}} \mathrm{dm}^{-3} ; \mathrm{P}$, extração em Mehlich, 14,4 $\mathrm{cmol}_{\mathrm{c}} \mathrm{dm}^{-3}$; S, 9,9 $\mathrm{Mg} \mathrm{dm}^{-3}$; MO, 19,0 $\mathrm{Mg} \mathrm{dm}^{-3}$; densidade de partícula, 2,54 $\mathrm{Mg} \mathrm{m}^{-3}$; capacidade de campo, $0,30 \mathrm{~m}^{3} \mathrm{~m}^{-3}$; e ponto de murcha permanente, $0,12 \mathrm{~m}^{3} \mathrm{~m}^{-3}$. A textura do solo nas camadas $0,0-0,5,0,05-0,10,0,10-0,20$ e $0,20-0,30 \mathrm{~m}$ era, respectivamente, de: areia, 232, 217, 213, $230 \mathrm{~g} \mathrm{~kg}^{-1}$; silte, 593, 598, 596 e $586 \mathrm{~g} \mathrm{~kg}^{-1}$; e argila, 175, 185, 191 e $183 \mathrm{~g} \mathrm{~kg}^{-1}$. A área encontrava-se sistematizada em cota zero e recebeu calagem com $3,5 \mathrm{Mg} \mathrm{ha}^{-1}$ de calcário, 45 dias antes da semeadura do milho. Nessa área, cultivou-se soja na safra anterior (2012/2013) e, antes da soja, cultivou-se arroz (2011/2012); nas entressafras, cultivou-se azevém. Após a colheita do arroz, realizou-se o último preparo, constituído de duas gradagens e aplainamento.

Utilizou-se o delineamento experimental de blocos ao acaso com quatro repetições, e os tratamentos testados foram: semeadura de milho, com semeadora equipada com discos duplos, em área escarificada 45 dias antes da semeadura, à profundidade de $0,25 \mathrm{~m}$, com hastes espaçadas a $0,35 \mathrm{~m}$ (ESC); semeadura do milho, com semeadora equipada com haste sulcadora regulada para a profundidade de 0,18 m (HS); semeadura do milho, com semeadora equipada com haste sulcadora, regulada para a profundidade de 0,15 $\mathrm{m}$, com mecanismo de acomodação do sulco (HAS); semeadura do milho, com semeadora equipada com disco ondulado de 12 ondas, com profundidade de trabalho de $0,08 \mathrm{~m}$ (DO); semeadura do milho, com semeadora equipada com disco duplo desencontrado, com profundidade de trabalho de 0,10 m (DD); e semeadura do milho, com semeadora equipada com mecanismo para construção do microcamalhão, e com haste sulcadora com profundidade de $0,13 \mathrm{~m}$ (CA), que construiu o microcamalhão e, simultaneamente, realizou a semeadura. 
A escarificação foi realizada com o solo em consistência friável, com escarificador de 5 hastes, espaçadas em $0,35 \mathrm{~m}$; posteriomente, foi realizada a gradagem para destorroar e uniformizar o solo. Nos tratamentos ESC, HS, HAS, DD e DO, utilizouse semeadora-adubadora pantográfica com seis linhas, com espaçamento de $0,50 \mathrm{~m}$, com rodas limitadoras de profundidade e massa aproximada de 2,3 $\mathrm{Mg}$, marca Massey Ferguson, modelo MF 407, tendo-se utilizado o disco de corte liso para palha, de $0,47 \mathrm{~m}$ de diâmetro, com exceção do DO, em que tanto para o corte da palha quanto para abertura do sulco para deposição do fertilizante, foi utilizado disco ondulado de 12 ondas, com $0,47 \mathrm{~m}$ de diâmetro. As hastes utilizadas mediam $0,41 \mathrm{~m}$ de comprimento, $0,0127 \mathrm{~m}$ de largura e $0,0257 \mathrm{~m}$ de largura da ponteira, com ângulo de ataque de $14^{\circ}$, e os discos duplos desencontrados mediam 0,40 e 0,39 m de diâmetro. O sistema de acomodação do sulco, no tratamento HAS, consistiu de uma roda de ferro sobre o sulco de semeadura, posterior à haste sulcadora, e anterior aos mecanismos de semeadura. Para o tratamento com camalhão, utilizou-se semeadora camalhoneira com seis linhas em espaçamento de $0,50 \mathrm{~m}$ e massa aproximada de $3,7 \mathrm{Mg}$, marca Industrial KF, modelo Hyper Plus, composta por três aivecas responsáveis pela formação dos camalhões, com duas linhas de cultivo, posicionadas à borda de

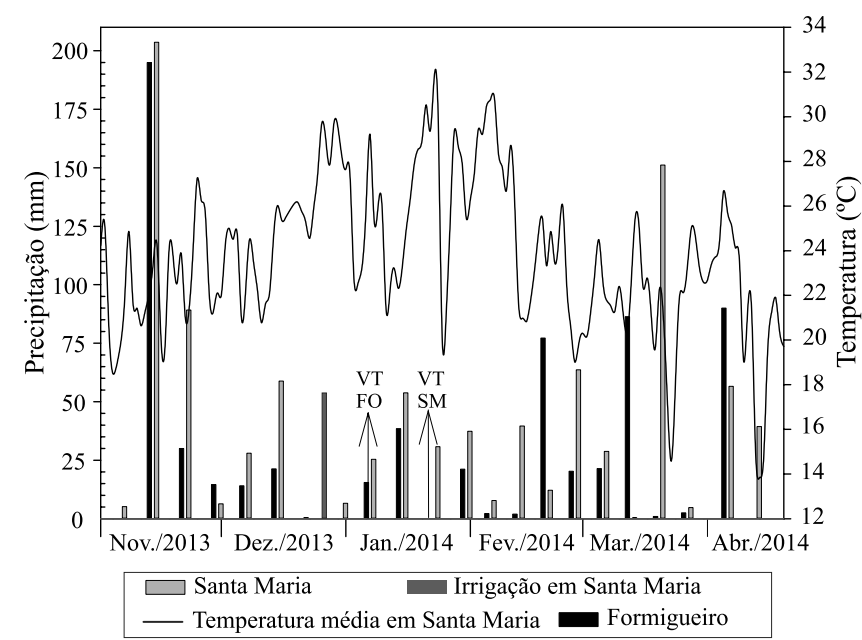

Figura 1. Precipitação pluvial e temperatura média do ar, na safra agrícola de 2013/2014, em Santa Maria, e precipitação em Formigueiro, durante o desenvolvimento da cultura do milho. VT FO, data de pendoamento do milho em Formigueiro; VT SM, pendoamento em Santa Maria . cada elevação com altura de $0,10 \mathrm{~m}$ em relação ao nível anterior do solo.

Nesse experimento, a semeadura do milho foi realizada no dia 07 de novembro de 2013. Em razão da baixa emergência de plantas, causada por precipitações superiores a $200 \mathrm{~mm}$ após a semeadura, nova semeadura foi realizada no dia 30 de novembro, no mesmo local. A adubação de base constituiu-se de $40 \mathrm{~kg} \mathrm{ha}^{-1}$ de N, $80 \mathrm{~kg} \mathrm{ha}^{-1}$ de $\mathrm{P}_{2} \mathrm{O}_{5}$ e $80 \mathrm{~kg} \mathrm{ha}^{-1}$ de $\mathrm{K}_{2} \mathrm{O}$ e, deste total, $30 \%$ foram aplicados na segunda semeadura. Durante a condução do experimento, foi feita uma irrigação por superfície, com lâmina de $54 \mathrm{~mm}$ de água, no dia 26 de dezembro de 2013, pois, o conteúdo de água do solo era inferior a $50 \%$ da capacidade de campo.

O segundo experimento foi realizado no município de Formigueiro, a $30^{\circ} 04^{\prime} \mathrm{S}, 53^{\circ} 37^{\prime} \mathrm{W}$ e $77 \mathrm{~m}$ de altitude. O solo foi classificado como Planossolo Háplico eutrófico típico, pertencente à unidade de mapeamento São Gabriel (Santos et al., 2013), com 0,25 m de horizonte $\mathrm{A}$ e as seguintes características químicas e físicas na camada de 0,0-0,2 m: $\mathrm{pH}\left(\mathrm{H}_{2} \mathrm{O} 1: 1\right) ; 5,3$, saturação por bases; 77,3\%; Al, $0,9 \mathrm{cmol}_{\mathrm{c}} \mathrm{dm}^{-3} ; \mathrm{Ca}$, $10,5 \mathrm{cmol}_{\mathrm{c}} \mathrm{dm}^{-3} ; \mathrm{Mg}, 8 \mathrm{cmol}_{\mathrm{c}} \mathrm{dm}^{-3} ; \mathrm{K}, 112 \mathrm{cmol}_{\mathrm{c}} \mathrm{dm}^{-3}$; $\mathrm{P}$, extração em Mehlich, 2,2 $\mathrm{cmol}_{\mathrm{c}} \mathrm{dm}^{-3} ; \mathrm{S}, 15 \mathrm{Mg} \mathrm{dm}^{-3}$; $\mathrm{MO}, 16,0 \mathrm{Mg} \mathrm{dm}^{-3}$; densidade de partícula 2,57 $\mathrm{Mg} \mathrm{m}^{-3}$; capacidade de campo, $0,30 \mathrm{~m}^{3} \mathrm{~m}^{-3}$; e ponto de murcha permanente, $0,09 \mathrm{~m}^{3} \mathrm{~m}^{-3}$. A textura do solo nas camadas $0,0-0,5,0,05-0,10,0,10-0,20$ e $0,20-0,30 \mathrm{~m}$ era respectivamente: areia, 250, 238, 205, $98 \mathrm{~g} \mathrm{~kg}^{-1}$; silte, 460, 454, 429 e $422 \mathrm{~g} \mathrm{~kg}^{-1}$; e argila, 290, 308, 366 e $480 \mathrm{~g} \mathrm{~kg}^{-1}$.

A área de instalação do experimento foi cultivada com forrageiras e pastejada por bovinos nos seis anos anteriores. Os tratamentos foram iguais aos testados em Santa Maria, com exceção da escarificação, que foi realizada no dia da semeadura e à profundidade dos discos duplos no tratamento DD $(0,08 \mathrm{~m})$ e dos discos ondulados no tratamento DO $(0,06 \mathrm{~m})$. Não se avaliou o tratamento $\mathrm{CA}$, pelo fato de a área apresentar declividade de $2 \%$. A semeadura do milho foi realizada no dia 05 de novembro de 2013, com adubação de base de $30 \mathrm{~kg} \mathrm{ha}^{-1}$ de N, $60 \mathrm{~kg} \mathrm{ha}^{-1}$ de $\mathrm{P}_{2} \mathrm{O}_{5}$ e $60 \mathrm{~kg} \mathrm{ha}^{-1}$ de $\mathrm{K}_{2} \mathrm{O}$.

Em ambos os experimentos, utilizou-se o híbrido 30F53YR da Pioneer, com densidade de semeadura de oito plantas por metro quadrado. A adubação nitrogenada de cobertura foi realizada nos estádios fenológicos V5 e V8, de acordo com a escala de 
Herman (1993), com a utilização de $75 \mathrm{~kg} \mathrm{ha}^{-1}$ de N, em cada aplicação, na forma de ureia. Os demais tratos culturais foram realizados conforme as recomendações técnicas para a cultura (Reunião..., 2013).

Aos 60 dias após a semeadura, as amostras de solo foram coletadas e as seguintes variáveis do solo foram determinadas: densidade, porosidade total, macroporosidade e microporosidade, pela coleta de amostras de solo com estrutura preservada no sulco de semeadura, com uma repetição para cada parcela, nas camadas de $0,00-0,05,0,05-0,10,0,10-0,20$ e $0,20-0,30 \mathrm{~m}$, com anéis de $0,04 \mathrm{~m}$ de altura e $0,04 \mathrm{~m}$ de diâmetro, com o método da mesa de tensão para as porosidades (Donagema et al., 2011).

Nos tratamentos ESC, HS e DD, nos dois experimentos, determinou-se a resistência do solo à penetração mecânica, na camada de $0,0-0,3 \mathrm{~m}$, no estádio VT, com penetrógrafo digital da marca Falker, modelo penetroLOG - PLG 1020 (Falker Automação, Porto Alegre, RS), em oito pontos por parcela. Esses pontos foram dispostos perpendicularmente às linhas de semeadura e equidistantes em $0,167 \mathrm{~m}$, seis nas entrelinhas e dois nos sulcos de semeadura, o que totalizou $1,36 \mathrm{~m}$ na largura das parcelas. As leituras foram realizadas em todas as repetições e, posteriormente, calculou-se a média para cada camada de $0,01 \mathrm{~m}$, em cada tratamento, para a confecção dos gráficos. No momento das avaliações, determinouse o conteúdo de água gravimétrico nos mesmos tratamentos que, posteriomente, foi corrigido para conteúdo volumétrico nas camadas $0,0-0,1,0,1-0,2$ e $0,2-0,3 \mathrm{~m}$ e, em seguida, calculou-se a média na camada 0-30 m. Nos mesmos tratamentos e estádio, no experimento de Santa Maria, avaliou-se a distribuição do sistema radicular do milho, por meio de abertura de trincheira perpendicular a duas linhas de semeadura. As raízes foram expostas e fotografadas com quadro de $1 \times 0,40 \mathrm{~m}$, composto por quadrículas de $0,05 \times 0,05 \mathrm{~m}$, e as raízes de cada quadrícula foram posteriormente desenhadas, de acordo com metodologia adaptada de Reichert et al. (2009).

Nos estádios V5 e VT, avaliou-se a estatura de planta e a produtividade de massa de matéria seca (MS). Para a determinação de estatura, mediram-se cinco plantas por unidade experimental, na segunda linha de semeadura. No estádio V5, estendeu-se a última folha, que foi medida até a ponta e, em VT, mediu-se até a inserção da última folha. Para a determinação da MS, cinco plantas foram secas em estufa, à temperatura de $65^{\circ} \mathrm{C}$, até a obtenção de massa constante, tendo-se estimado a MS por hectare (MS $\times$ população de plantas por hectare). A produtividade de grãos foi estimada pela colheita das espigas de milho em 7,5 $\mathrm{m}^{2}$ de cada unidade experimental. Após a colheita, realizou-se a trilha, a pesagem e a retirada de impurezas dos grãos, a correção da umidade para $13 \%$ e a transformação dos resultados para $\mathrm{Mg} \mathrm{ha}^{-1}$.

Os dados foram submetidos ao teste das pressuposições do modelo matemático: normalidade, pelo teste de Shapiro-Wilk; e homogeneidade das variâncias, pelo teste de Bartlett. A análise da variância foi realizada com o teste $\mathrm{F}$ e, quando significativas, as médias foram comparadas pelo teste de Tukey, a 5\% de probabilidade, com o auxílio do programa Assistat, versão 7.7 beta (Universidade Federal de Campina Grande, Campina Grande, PB).

\section{Resultados e Discussão}

No experimento de Formigueiro, a densidade do solo no sulco de semeadura foi reduzida em $12 \%$, nos tratamentos ESC, HAS e HS, nas camadas 0,05-0,10 e $0,10-0,20 \mathrm{~m}$, o que resultou em aumento de $18 \%$ da porosidade total e $58 \%$ da macroporosidade (Tabela 1). Em Santa Maria, a densidade do solo, a porosidade total e a macroporosidade foram similares. Essa maior resposta em Formigueiro está associada à compactação nessa área, proporcionada pelos animais nos anos anteriores, enquanto, em Santa Maria, a densidade natural do solo é maior em consequência do menor teor de argila, em comparação à Formigueiro (Marcolin \& Klein, 2011). Além disso, a ressemeadura no mesmo sulco de semeadura, realizada em Santa Maria, pode ter contribuído para reduzir as diferenças obtidas nesses atributos, pois houve o efeito dos tratamentos, nas duas vezes.

Em Santa Maria, os tratamentos DO e DD atingiram profundidade de 0,08 e $0,10 \mathrm{~m}$, respectivamente e, em Formigueiro, essas profundidades foram de 0,06 e $0,08 \mathrm{~m}$, respectivamente (Figura 2). Este resultado é explicado como decorrente do uso do disco de corte ondulado de 12 ondas, que possibilita maior mobilização do solo e, desta forma, exige maior força vertical para atingir maior profundidade (Silva et al., 2012), ou seja, maior massa por linha do que o disco duplo. 
Tabela 1. Densidade, porosidade total, macroporosidade e microporosidade do solo no sulco de semeadura, nas camadas de $0,0-0,05,0,05-0,10,0,10-0,20$ e $0,20-0,30 \mathrm{~m}$, em dois experimentos de escarificação mecanizada do solo e diferentes sulcadores em semeadora, para o cultivo de milho em Planossolo ${ }^{(1)}$.

\begin{tabular}{|c|c|c|c|c|c|c|c|c|}
\hline \multirow{2}{*}{$\begin{array}{l}\text { Camada } \\
(\mathrm{m})\end{array}$} & \multicolumn{6}{|c|}{ Tratamento } & \multirow[t]{2}{*}{ Média } & \multirow{2}{*}{$\begin{array}{l}\mathrm{CV} \\
(\%)\end{array}$} \\
\hline & ESC & HAS & HS & DO & DD & $\mathrm{CA}$ & & \\
\hline & & & ---- & -- Santa & ------ & 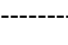 & & \\
\hline & \multicolumn{8}{|c|}{ Densidade do solo $\left(\mathrm{Mg} \mathrm{m}^{-3}\right)$} \\
\hline $0,00-0,05$ & $1,19^{\mathrm{ns}}$ & 1,28 & 1,27 & 1,28 & 1,24 & 1,25 & 1,25 & 5,26 \\
\hline $0,05-0,10$ & $1,42^{\text {ns }}$ & 1,37 & 1,35 & 1,47 & 1,49 & 1,46 & 1,43 & 6,02 \\
\hline $0,10-0,20$ & $1,54^{\mathrm{ns}}$ & 1,49 & 1,45 & 1,53 & 1,57 & 1,41 & 1,50 & 4,74 \\
\hline \multirow[t]{2}{*}{$\underline{0,20-0,30}$} & $1,63^{\mathrm{ns}}$ & 1,58 & 1,56 & 1,64 & 1,62 & 1,55 & 1,60 & 3,59 \\
\hline & \multicolumn{8}{|c|}{ Porosidade total do solo $\left(\mathrm{m}^{3} \mathrm{~m}^{-3}\right)$} \\
\hline $0,00-0,05$ & $0,53^{\mathrm{ns}}$ & 0,50 & 0,50 & 0,50 & 0,51 & 0,51 & 0,51 & 4,95 \\
\hline $0,05-0,10$ & $0,44^{\mathrm{ns}}$ & 0,46 & 0,47 & 0,43 & 0,42 & 0,43 & 0,44 & 7,97 \\
\hline $0,10-0,20$ & $0,40^{\mathrm{ns}}$ & 0,42 & 0,43 & 0,40 & 0,38 & 0,45 & 0,41 & 6,86 \\
\hline \multirow[t]{2}{*}{$\underline{0,20-0,30}$} & $0,36^{\mathrm{ns}}$ & 0,38 & 0,39 & 0,36 & 0,36 & 0,39 & 0,37 & 6,15 \\
\hline & \multicolumn{8}{|c|}{ Macroporosidade do solo $\left(\mathrm{m}^{3} \mathrm{~m}^{-3}\right)$} \\
\hline $0,00-0,05$ & $0,27^{\mathrm{ns}}$ & 0,24 & 0,25 & 0,22 & 0,26 & 0,25 & 0,25 & 15,88 \\
\hline $0,05-0,10$ & $0,19^{\text {ns }}$ & 0,23 & 0,21 & 0,18 & 0,17 & 0,19 & 0,20 & 19,96 \\
\hline $0,10-0,20$ & $0,15^{\mathrm{ns}}$ & 0,17 & 0,18 & 0,15 & 0,15 & 0,21 & 0,17 & 28,04 \\
\hline \multirow[t]{2}{*}{$\underline{0,20-0,30}$} & $0,09^{\text {ns }}$ & 0,11 & 0,13 & 0,11 & 0,11 & 0,11 & 0,11 & 26,06 \\
\hline & \multicolumn{8}{|c|}{ Microporosidade do solo $\left(\mathrm{m}^{3} \mathrm{~m}^{-3}\right)$} \\
\hline $0,00-0,05$ & $0,27^{\mathrm{ns}}$ & 0,26 & 0,25 & 0,28 & 0,26 & 0,26 & 0,26 & 10,23 \\
\hline $0,05-0,10$ & $0,25^{\text {ns }}$ & 0,23 & 0,26 & 0,24 & 0,24 & 0,24 & 0,24 & 7,91 \\
\hline $0,10-0,20$ & $0,25^{\mathrm{ns}}$ & 0,25 & 0,25 & 0,25 & 0,23 & 0,24 & 0,25 & 12,02 \\
\hline \multirow[t]{3}{*}{$\underline{0,20-0,30}$} & $0,27^{\mathrm{ns}}$ & 0,27 & 0,26 & 0,25 & 0,25 & 0,28 & 0,26 & 8,94 \\
\hline & ------- & 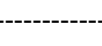 & ------- & ormigue & ---------- & -----. & -------. & -------- \\
\hline & \multicolumn{8}{|c|}{ Densidade do solo $\left(\mathrm{Mg} \mathrm{m}^{-3}\right)$} \\
\hline $0,00-0,05$ & $1,15^{\mathrm{ns}}$ & 1,23 & 1,24 & 1,19 & 1,34 & - & 1,15 & 7,10 \\
\hline $0,05-0,10$ & $1,28 \mathrm{c}$ & $1,38 \mathrm{bc}$ & $1,31 \mathrm{bc}$ & $1,50 \mathrm{ab}$ & $1,52 \mathrm{a}$ & - & 1,28 & 6,62 \\
\hline $0,10-0,20$ & $1,38 \mathrm{ab}$ & $1,32 \mathrm{~b}$ & $1,31 \mathrm{~b}$ & $1,54 \mathrm{a}$ & $1,53 \mathrm{a}$ & - & 1,38 & 6,20 \\
\hline \multirow[t]{2}{*}{$\underline{0,20-0,30}$} & $1,33^{\text {ns }}$ & 1,30 & 1,26 & 1,37 & 1,34 & - & 1,33 & 5,60 \\
\hline & \multicolumn{8}{|c|}{ Porosidade total do solo $\left(\mathrm{m}^{3} \mathrm{~m}^{-3}\right)$} \\
\hline $0,00-0,05$ & $0,55^{\mathrm{ns}}$ & 0,52 & 0,51 & 0,53 & 0,47 & - & 0,52 & 6,58 \\
\hline $0,05-0,10$ & $0,50 \mathrm{a}$ & $0,46 \mathrm{ab}$ & $0,49 \mathrm{a}$ & $0,41 \mathrm{ab}$ & $0,40 \mathrm{~b}$ & - & 0,45 & 7,85 \\
\hline $0,10-0,20$ & $0,46 \mathrm{ab}$ & $0,48 \mathrm{a}$ & $0,49 \mathrm{a}$ & $0,40 \mathrm{~b}$ & $0,40 \mathrm{~b}$ & - & 0,45 & 7,73 \\
\hline \multirow[t]{2}{*}{$\underline{0,20-0,30}$} & $0,48^{\text {ns }}$ & 0,49 & 0,49 & 0,46 & 0,47 & - & 0,48 & 6,07 \\
\hline & \multicolumn{8}{|c|}{ Macroporosidade do solo $\left(\mathrm{m}^{3} \mathrm{~m}^{-3}\right)$} \\
\hline $0,00-0,05$ & $0,24^{\mathrm{ns}}$ & 0,24 & 0,23 & 0,24 & 0,17 & - & 0,24 & 23,57 \\
\hline $0,05-0,10$ & $0,16 a b$ & $0,17 \mathrm{ab}$ & $0,21 \mathrm{a}$ & $0,11 b$ & $0,11 b$ & - & 0,22 & 30,81 \\
\hline $0,10-0,20$ & $0,16^{\mathrm{ns}}$ & 0,17 & 0,15 & 0,10 & 0,11 & - & 0,15 & 26,19 \\
\hline \multirow[t]{2}{*}{$\underline{0,20-0,30}$} & $0,06^{\mathrm{ns}}$ & 0,11 & 0,14 & 0,05 & 0,06 & - & 0,14 & 54,81 \\
\hline & \multicolumn{8}{|c|}{ Microporosidade do solo $\left(\mathrm{m}^{3} \mathrm{~m}^{-3}\right)$} \\
\hline $0,00-0,05$ & $0,31^{\mathrm{ns}}$ & 0,28 & 0,28 & 0,29 & 0,31 & - & 0,29 & 10,90 \\
\hline $0,05-0,10$ & $0,33^{\text {ns }}$ & 0,29 & 0,28 & 0,30 & 0,29 & - & 0,29 & 10,94 \\
\hline $0,10-0,20$ & $0,30^{\mathrm{ns}}$ & 0,32 & 0,34 & 0,30 & 0,29 & - & 0,30 & 12,00 \\
\hline $0,20-0,30$ & $0,42^{\text {ns }}$ & 0,38 & 0,37 & 0,41 & 0,41 & - & 0,31 & 16,47 \\
\hline
\end{tabular}

${ }^{(1)}$ Médias seguidas por letras iguais, na linha, não diferem entre si, pelo teste de Tukey, a 5\% de probabilidade. ns Não significativo. Tratamentos: ESC, escarificação do solo e semeadura com disco duplo; HAS, semeadura direta com haste sulcadora e mecanismo de acomodação do sulco na semeadora; HS, semeadura direta com haste sulcadora na semeadora; DD, semeadura direta com disco duplo desencontrado na semeadora; DO, semeadura direta com disco ondulado; e CA, semeadura direta com haste sulcadora e construção concomitante de microcamalhão em Santa Maria. 

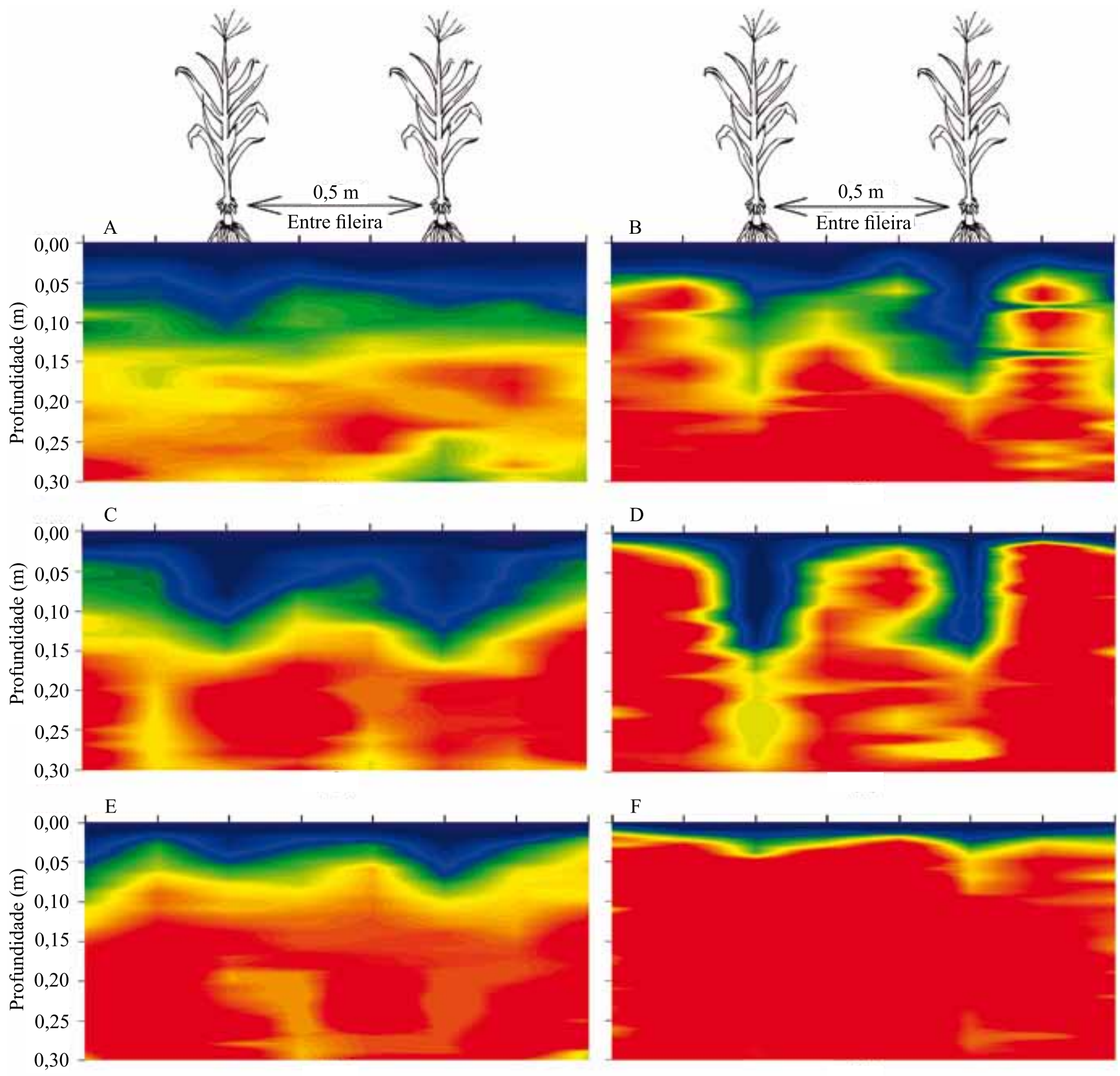

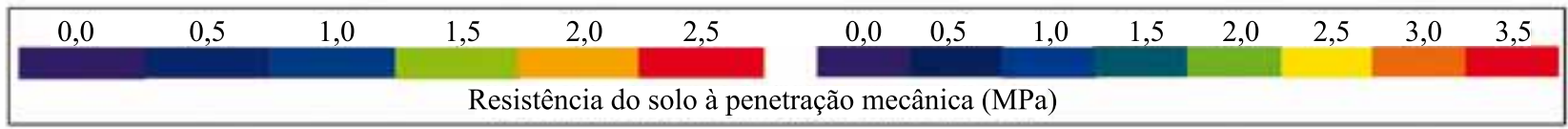

Figura 2. Distribuição da resistência do solo à penetração mecânica perpendicular aos sulcos de semeadura, com penetrógrafo digital da marca Falker, modelo penetroLOG - PLG 1020: (A, B) em solo escarificado a 0,25 m de profundidade e semeadura com disco duplo na semeadora; (C, D) semeadura direta com haste sulcadora com profundidade de $0,18 \mathrm{~m}$; e (E, F) semeadura direta com disco duplo desencontrado, com profundidade de 0,10 m, em Santa Maria, e 0,08 m em Formigueiro. Santa Maria $(\mathrm{A}, \mathrm{C}, \mathrm{E})$ e Formigueiro $(\mathrm{B}, \mathrm{D}, \mathrm{F})$, conteúdo de água do solo de 0,29 e $0,18 \mathrm{~m}^{3} \mathrm{~m}^{-3}$, respectivamente, na média da camada de $0,0-0,30 \mathrm{~m}$. 
Em Formigueiro, a densidade do solo nos tratamentos DD e DO foi superior a $1,50 \mathrm{Mg} \mathrm{m}^{-3}$, enquanto nos demais tratamentos, ela ficou abaixo de $1,38 \mathrm{Mg} \mathrm{m}^{-3}$, nas camadas $0,05-0,10$ e $0,10-0,20 \mathrm{~m}$, no sulco de semeadura. Essa maior densidade, nesses dois tratamentos, evidencia que esses mecanismos não foram eficazes para reduzir o aumento de densidade proveniente do pisoteio de animais na área, durante os seis anos que antecederam a instalação do experimento. Resultados semelhantes foram encontrados por Collares et al. (2011), que observaram aumento da densidade e redução da macroporosidade, em áreas que utilizam o sistema de integração lavoura-pecuária, e por Modolo (2013), em solo compactado por alta lotação de animais, em que o uso de sulcador do tipo disco duplo não foi suficiente para reduzir os efeitos da compactação, em comparação ao uso da haste sulcadora.

Em ambos os experimentos, os sulcadores mobilizaram o solo na camada mais superficial $(0,00-0,05 \mathrm{~m})$, em que as variáveis físicas do solo foram similares (Tabela 1). Além disso, essa camada é influenciada pelas ações biológicas, desenvolvimento radicular e ciclos de umedecimento e secagem, processos estes que favorecem a agregação do solo e, consequentemente, a redução da densidade (Six et al., 2004). Na camada mais profunda $(0,20-0,30 \mathrm{~m})$, não houve diferença significativa entre os tratamentos avaliados quanto aos atributos físicos do solo.

A RP foi determinada à umidade de 0,29 e $0,18 \mathrm{~m}^{3} \mathrm{~m}^{-3}$, em Santa Maria e Formigueiro, respectivamente, na média da camada de $0,0-0,3 \mathrm{~m}$, e foi igual nos tratamentos em que a RP foi determinada. As maiores variações RP em Formigueiro (Figura 2), em comparação a Santa Maria, estão relacionadas ao manejo anterior dessa área, onde os bovinos promoveram o adensamento do solo, nas safras anteriores. Além disso, o menor conteúdo de água no solo, em Formigueiro, pode ter favorecido as maiores diferenças nesse experimento. Reichert et al. (2009) encontraram RP similar, em manejos de solo com conteúdo de água próximo de $0,25 \mathrm{~m}^{3} \mathrm{~m}^{-3}$, enquanto com conteúdo de água próximo a $0,15 \mathrm{~m}^{3} \mathrm{~m}^{-3}$, a RP, para o plantio direto, foi maior do que em solo escarificado. A RP tem grande variação com a mudança do conteúdo de água do solo (Bengough et al., 2006; Assis et al., 2009), pois a água reduz o atrito entre as partículas (Assis et al., 2009).
Nos dois experimentos, o tratamento ESC proporcionou valores menores de RP, em todo perfil do solo até profundidade de $0,20 \mathrm{~m}$, e foi menor em superfície e maior em profundidade (Figuras 2). Nos tratamentos HS e DD, observou-se menor RP no sulco de semeadura, porém, no HS, essa redução de RP ocorreu até $0,18 \mathrm{~m}$, em ambos os solos, enquanto no DD houve redução até 0,10 e 0,08 , em Santa Maria e Formigueiro, respectivamente.

$O$ padrão de distribuição do sistema radicular foi semelhante ao da variável RP (Figura 3). Nos tratamentos ESC e HS, as raízes atingiram profundidade de $0,25 \mathrm{~m}$, porém no ESC elas se distribuiram mais uniformemente e, no HS, elas se concentraram no sulco de semeadura. No tratamento $\mathrm{DD}$, as raízes atingiram a profundidade de $0,15 \mathrm{~m} \mathrm{e}$ se concentraram mais superficialmente. Segundo Bengough et al. (2006), o crescimento radicular está relacionado às restrições físicas do solo, e os efeitos desse menor crescimento sobre a produtividade de grãos está relacionado ao tempo em que as plantas serão submetidas a esse estresse.

O conteúdo de água do solo menor do que $60 \%$ da capacidade de campo $\left(0,30 \mathrm{~m}^{3} \mathrm{~m}^{-3}\right)$ reduz o desenvolvimento das culturas (Bergamaschi et al., 2006). Em Santa Maria, a diferença entre a capacidade de campo e esse conteúdo restritivo de água no solo $\left(0,18 \mathrm{~m}^{3} \mathrm{~m}^{-3}\right)$ foi de $0,12 \mathrm{~m}^{3} \mathrm{~m}^{-3}$. Assim, a cada camada de $0,1 \mathrm{~m}$ de solo, a lâmina de água disponível era de $12 \mathrm{~mm}$. Nos tratamentos ESC e HS, em que as raízes chegaram à profundidade de 0,25 m (Figura 3), a lâmina de água era de $30 \mathrm{~mm}$. No tratamento DD, em que as raízes atingiram a profundidade de $0,15 \mathrm{~m}$, a lâmina era de $18 \mathrm{~mm}$. Se não ocorresse precipitação ou irrigação, depois de o solo atingir a umidade de capacidade campo, com uma evapotranspiração média de 4,35 $\mathrm{mm} \mathrm{dia}^{-1}$ (Bergamaschi et al., 2006), nos tratamentos ESC e HS, a cultura do milho teria redução de desenvolvimento a partir do $7^{\circ}$ dia, enquanto no DD isso ocorreria a partir do $4^{\circ}$ dia.

A estatura de planta, a altura de inserção de espiga e a produtividade de massa de matéria seca, no estádio V5, foram menores nos tratamentos DD e DO, nos dois experimentos (Tabela 2). No estádio VT (pendoamento), em Formigueiro, os valores de estatura e massa de matéria seca acumulada por hectare foram maiores no ESC, HS e HAS do que nos tratamentos DD e DO. Em Santa Maria, a estatura no estádio

Pesq. agropec. bras., Brasília, v.51, n.3, p.261-270, mar. 2016 DOI: 10.1590/S0100-204X2016000300008 
VT não diferiu entre os tratamentos, mas a massa de matéria seca, nesse estádio, e a altura de inserção da espiga foram menores no DD e DO do que no ESC, HS, HAS e CA. As produtividades de grãos obtidas em Santa Maria foram maiores em 25\%, na média dos tratamentos CA, ESC, HS e HAS, em comparação ao DO e DD e, em Formigueiro, os tratamentos ESC, HS e HAS foram superiores em $20 \%$.

Embora a produtividade de grãos obtida no tratamento CA tenha sido igual à dos tratamentos ESC, HS e HAS, a associação da haste sulcadora com a drenagem superficial mais eficiente pode ser importante em situações de elevadas precipitações pluviais. Fiorin et al. (2009) verificaram produtividade menor de massa de matéria fresca e massa de matéria seca, em condições de excesso hídrico. Modolo et al. (2013) obtiveram produtividade maior de grãos de milho com o uso da haste sulcadora, em áreas de maior compactação do solo, do que com semeadura com disco duplo, em consequência da alta lotação animal por unidade de área. Os autores verificaram resultados semelhantes entre o mecanismo sulcador disco duplo e a haste sulcadora, quando a densidade do solo e a porosidade não são restritivas ao desenvolvimento da planta de milho.

A maior produtividade de grãos em Santa Maria, em relação à obtida em Formigueiro, pode ser explicada, em parte, pela irrigação por superfície, realizada no dia 26 de dezembro, com lâmina de $54 \mathrm{~mm}$ (Figura 1), quando o solo atingiu conteúdo de água em $50 \%$ da capacidade de campo. Em Formigueiro, houve um período de três semanas sem precipitações significativas, na segunda metade de dezembro e na primeira semana de janeiro. $\mathrm{O}$ pendoamento pleno ocorreu no final da primeira semana de janeiro, tendo coincidido a baixa disponibilidade hídrica com o período antecedente ao pendoamento (Figura 1). Esse momento, juntamente com o período pós-floração, são os períodos mais sensíveis da cultura do milho ao deficit hídrico (Bergamaschi et al., 2006).

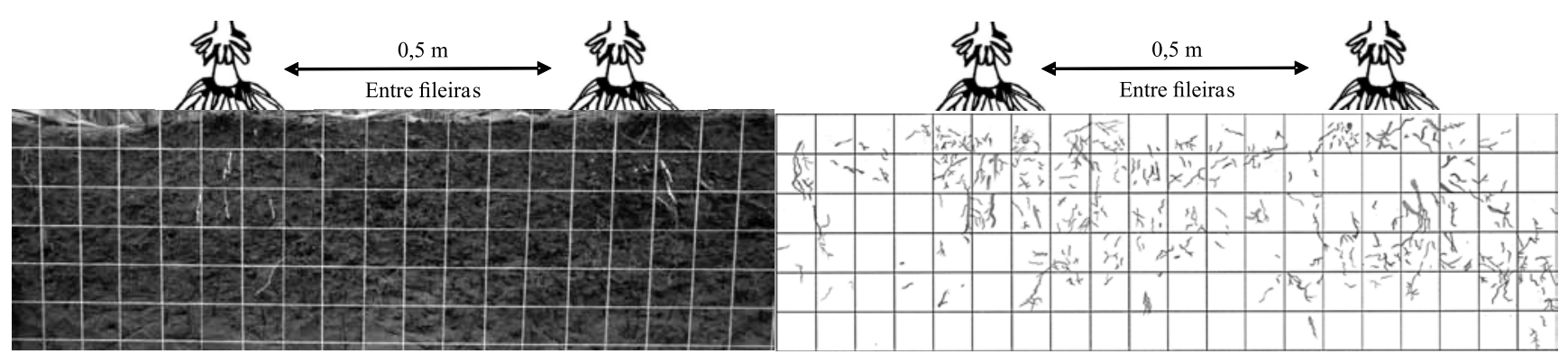

Escarificação do solo, antes da semeadura do milho com disco duplo

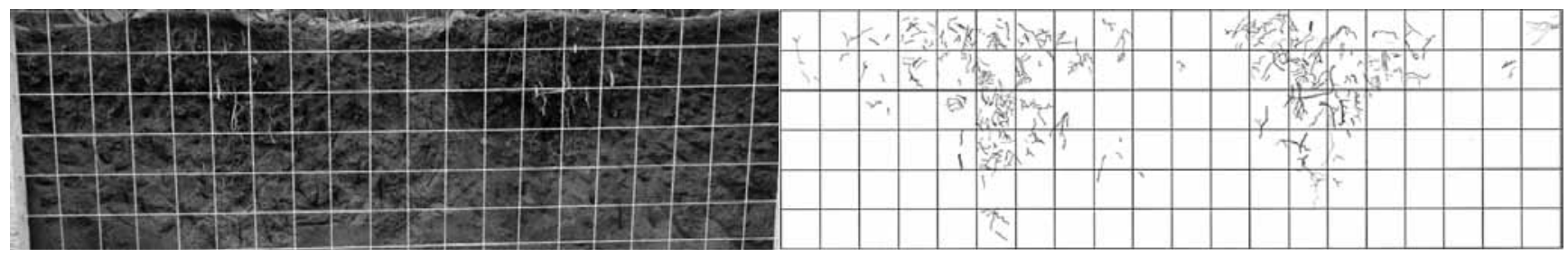

Semeadura direta com haste sulcadora na semeadora

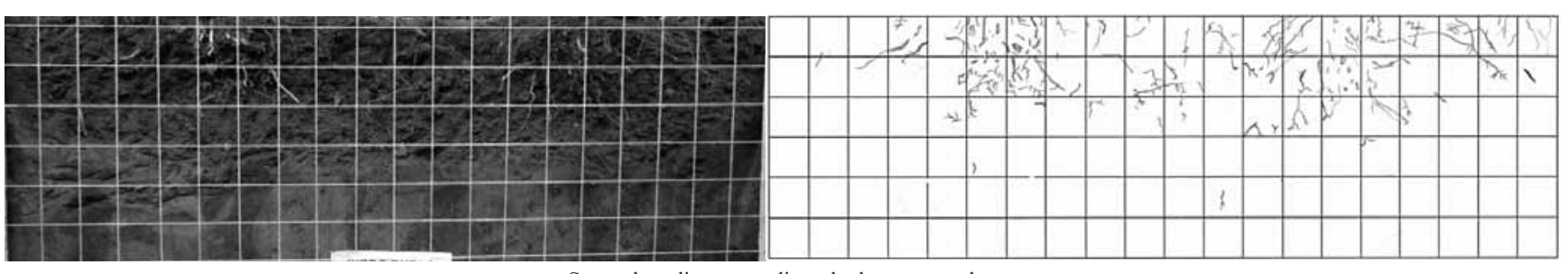

Semeadura direta com disco duplo na semeadora

Figura 3. Distribuição espacial do sistema radicular de milho, no estádio de pendoamento, com fotografia de trincheira (esquerda) e desenho das raízes (direita) em malha de 0,05x0,05 m, em Santa Maria, RS. 
Tabela 2. Estatura de planta e produtividade de massa de matéria seca da parte aérea, nos estádios V5 e VT, altura de inserção da espiga e produtividade de grãos de milho, em dois experimentos de escarificação mecanizada do solo e diferentes sulcadores em semeadora, para o cultivo de milho em Planossolos ${ }^{(1)}$.

\begin{tabular}{|c|c|c|c|c|c|c|}
\hline \multirow[t]{2}{*}{ Tratamento } & \multicolumn{2}{|c|}{ Estatura $(\mathrm{m})$} & \multicolumn{2}{|c|}{ Massa de matéria seca $\left(\mathrm{Mg} \mathrm{ha}^{-1}\right)$} & \multirow{2}{*}{$\begin{array}{c}\text { Altura de inserção } \\
\text { da espiga }(\mathrm{m})\end{array}$} & \multirow{2}{*}{$\begin{array}{l}\text { Produtividade de } \\
\text { grãos }\left(\mathrm{Mg} \mathrm{ha}^{-1}\right)\end{array}$} \\
\hline & V5 & VT & V5 & VT & & \\
\hline & \multicolumn{6}{|c|}{ 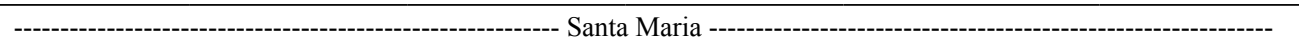 } \\
\hline Escarificação & $0,91 \mathrm{ab}$ & $2,01^{\text {ns }}$ & $0,89 \mathrm{ab}$ & $12,49 \mathrm{ab}$ & $1,42 \mathrm{a}$ & $6,97 \mathrm{ab}$ \\
\hline Haste com acomodação do sulco & $0,93 \mathrm{ab}$ & 2,07 & $0,79 \mathrm{ab}$ & $12,99 \mathrm{ab}$ & $1,38 \mathrm{a}$ & $6,93 \mathrm{ab}$ \\
\hline Haste sulcadora & $0,95 \mathrm{a}$ & 1,98 & $0,82 \mathrm{ab}$ & $11,50 \mathrm{ab}$ & $1,34 \mathrm{a}$ & $7,24 \mathrm{a}$ \\
\hline Disco ondulado & $0,80 \mathrm{~b}$ & 1,90 & $0,57 \mathrm{~b}$ & $8,22 \mathrm{~b}$ & $1,24 \mathrm{~b}$ & $5,55 \mathrm{c}$ \\
\hline Disco duplo & $0,84 \mathrm{ab}$ & 1,92 & $0,63 \mathrm{ab}$ & $11,06 \mathrm{ab}$ & $1,22 b$ & $5,91 b c$ \\
\hline Camalhão & $0,94 \mathrm{a}$ & 2,08 & $1,02 \mathrm{a}$ & $14,44 \mathrm{a}$ & $1,38 \mathrm{a}$ & $7,69 \mathrm{a}$ \\
\hline Média & 0,89 & 2,00 & 0,79 & 11,78 & 1,33 & 6,66 \\
\hline \multirow[t]{2}{*}{ CV (\%) } & 6,22 & 4,72 & 24,24 & 22,37 & 3,47 & 8,15 \\
\hline & \multicolumn{6}{|c|}{ 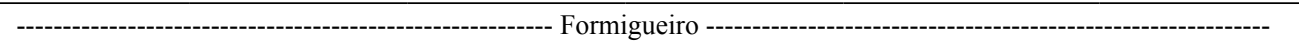 } \\
\hline Escarificação & $0,93 \mathrm{a}$ & $1,75 \mathrm{a}$ & $1,65 \mathrm{a}$ & $12,60 \mathrm{a}$ & $1,06 \mathrm{a}$ & $5,31 \mathrm{a}$ \\
\hline Haste com acomodação do sulco & $0,86 \mathrm{a}$ & $1,65 \mathrm{ab}$ & $1,07 \mathrm{a}$ & $9,50 \mathrm{~b}$ & $103 \mathrm{a}$ & $4,81 \mathrm{ab}$ \\
\hline Haste sulcadora & $0,89 \mathrm{a}$ & $1,66 \mathrm{a}$ & $1,08 \mathrm{a}$ & $9,48 b$ & $102 \mathrm{a}$ & $5,08 \mathrm{a}$ \\
\hline Disco ondulado & $0,63 b$ & $1,50 \mathrm{c}$ & $0,41 b$ & $5,05 \mathrm{c}$ & $88 \mathrm{~b}$ & $4,13 b$ \\
\hline Disco duplo & $0,64 \mathrm{~b}$ & $1,50 \mathrm{bc}$ & $0,42 b$ & $6,58 \mathrm{c}$ & $89 \mathrm{~b}$ & $4,28 \mathrm{~b}$ \\
\hline Média & 0,79 & 1,61 & 0,93 & 8,69 & 0,98 & 4,72 \\
\hline CV (\%) & 9,21 & 4,23 & 29,81 & 15,63 & 2,25 & 7,15 \\
\hline
\end{tabular}

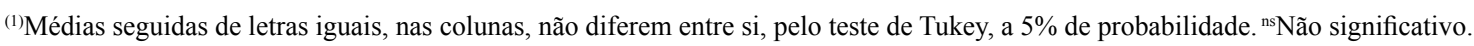

As maiores produtividades de grãos foram obtidas nos tratamentos com maior mobilização do solo e estão relacionadas à redução da $\mathrm{RP}$, ao aumento da macroporosidade na região de maior concentração do sistema radicular, à maior profundidade e à melhor distribuição do sistema radicular. Assim, a cultura apresentou menores restrições ocasionadas por estresses por deficiência ou excesso hídrico.

Deve-se ressaltar que a semeadura sobre camalhão, a escarificação do solo e o uso de haste sulcadora demandam maior força para tração, o que resulta em maior consumo de combustível e maior demanda de potência do trator (Mion \& Benez, 2008). Assim, na escolha do sistema de implantação, deve-se considerar o retorno econômico.

\section{Conclusões}

1. A escarificação do solo e a semeadura direta com haste sulcadora reduzem a resistência do solo à penetração mecânica, para implantação de milho em Planossolos.

2. A produtividade de grãos de milho em Planossolos é maior, quando a semeadura é realizada sobre camalhão, solo escarificado ou semeadura direta com haste sulcadora na semeadora.

\section{Referências}

ALVARES, C.A.; STAPE, J.L.; SENTELHAS, P.C.; GONÇALVES, J.L. de M.; SPAROVEK, G. Köppen's climate classification map for Brazil. Meteorologische Zeitschrift, v.22, p.711-728, 2013. DOI: 10.1127/0941-2948/2013/0507.

ANDRES, A.; AVILA, L.A. de; MARCHEZAN, E.; MENEZES, V.G. Rotação de culturas e pousio do solo na redução do banco de sementes de arroz vermelho em solo de várzea. Revista Brasileira de Agrociência, v.7, p.85-88, 2001.

ASSIS, R.L. de; LAZARINI, G.D.; LANÇAS, K.P.; CARGNELUTTI FILHO, A. Avaliação da resistência do solo à penetração em diferentes solos com a variação do teor de água. Engenharia Agrícola, v.29, p.558-568, 2009. DOI: 10.1590/ S0100-69162009000400006.

BAMBERG, A.L.; PAULETTO, E.A.; GOMES, A. da S.; TIMM, L.C.; PINTO, L.F.S.; LIMA, A.C.R. de; SILVA, T.R. da. Densidade de um Planossolo sob sistemas de cultivo avaliada por meio da tomografia computadorizada de raios gama. Revista Brasileira de Ciência do Solo, v.33, p.1079-1086, 2009. DOI: 10.1590/S0100-06832009000500001.

BENGOUGH, A.G.; BRANSBY, M.F.; HANS, J.; MCKENNA, S.J.; ROBERTS, T.J.; VALENTINE, T.A. Root responses to soil physical conditions; growth dynamics from field to cell. Journal of Experimental Botany, v.57, p.437-447, 2006. DOI: 10.1093/ jxb/erj003.

BERGAMASCHI, H.; DALMAGO, G.A.; COMIRAN, F.; BERGONCI, J.I.; MÜlLER, A.G.; FRANÇA, S.; SANTOS, A.O.; RADIN, B.; BIANCHI, C.A.M.; PEREIRA, P.G. 
Deficit hídrico e produtividade na cultura do milho. Pesquisa Agropecuária Brasileira, v.41, p.243-249, 2006. DOI: 10.1590/ S0100-204X2006000200008.

COLET, M.J.; SVERZUT, C.B.; WEIRICH NETO, P.H.; SOUZA, Z.M. de. Alteração em atributos físicos de um solo sob pastagem após escarificação. Ciência e Agrotecnologia, v.33, p. 361-368, 2009. DOI: $10.1590 / \mathrm{S} 1413-70542009000200001$.

COLLARES, G.L.; REINERT, D.J.; REICHERT, J.M.; KAISER, D.R. Compactação superficial de Latossolos sob integração lavoura-pecuária de leite no noroeste do Rio Grande do Sul. Ciência Rural, v.41, p.246-250, 2011. DOI: 10.1590/ S0103-84782011000200011.

DONAGEMA, G.K.; CAMPOS, D.V.B. de; CALDERANO, S.B.; TEIXEIRA, W.G.; VIANA, J.H.M. (Org.). Manual de métodos de análise de solo. 2.ed. rev. Rio de Janeiro: Embrapa Solos, 2011. $230 \mathrm{p}$.

DRESCHER, M.S.; ELTZ, F.L.F.; DENARDIN, J.E.; FAGANELLO, A. Persistência do efeito de intervenções mecânicas para a descompactação de solos sob plantio direto. Revista Brasileira de Ciência do Solo, v.35, p.1713-1722, 2011. DOI: $10.1590 / \mathrm{S} 0100-06832011000500026$.

FIORIN, T.T.; SPOHR, R.B.; CARLESSO, R.; MICHELON, C.J.; SANTA, C.D.; DAVID, G. de. Produção de silagem de milho sobre camalhões em solos de várzea. Pesquisa Aplicada e Agrotecnologia, v.2, p.147-153, 2009. DOI: 10.5777/paet. v2i1.442.

HERMAN, J.C. (Ed.). How a Corn plant develops. , Ames: Iowa State University of Science and Technology, 1993. Special Report n. ${ }^{\circ} 48$.

MARCOLIN, C.D.; KLEIN, V.A. Determinação da densidade relativa do solo por uma função de pedotransferência para a densidade do solo máxima. Acta Scientiarum Agronomy, v.33, p.349-354, 2011. DOI: 10.4025/actasciagron.v33i2.6120.

MATZENBACHER, F.O.; KALSING, A.; MENEZES, V.G; BARCELOS, J.A.N.; MEROTTO JUNIOR, A. Rapid diagnosis of resistance to imidazolinone herbicides in barnyardgrass (Echinochloa crus-galli) and control of resistant biotypes with alternative herbicides. Planta daninha, v.31, p.645-656, 2013. DOI: $10.1590 / \mathrm{S} 0100-83582013000300016$.

MION, R.L.; BENEZ, S.H. Esforços em ferramentas rompedoras de solo de semeadoras de plantio direto. Ciência e Agrotecnologia, v.32, p.1594-1600, 2008. DOI: 10.1590/ S1413-70542008000500036.

MODOLO, A.J.; FRANCHIN, M.F.; TROGELlO, E.; ADAMI, P.F.; SCARSI, M.; CARNIELETTO, R. Semeadura de milho com dois mecanismos sulcadores sob diferentes intensidades de pastejo.
Engenharia Agrícola, v.33, p.1200-1209, 2013. DOI: 10.1590/ S0100-69162013000600013.

MORAES, M.T. de; DEBIASI, H.; FRANCHINI, J.C.; SILVA, V.R. da. Soil penetration resistance in a rhodic eutrudox affected by machinery traffic and soil water content. Engenharia Agrícola, v.33, p.748-757, 2013. DOI: 10.1590/S0100-69162013000400014.

PINTO, L.F.S.; LAUS NETO, J.A.; PAULETTO, E.A. Solos de várzea do Sul do Brasil cultivados com arroz irrigado. In: GOMES, A. da S.; MAGALHÃES JÚNIOR, A.M. de (Ed.). Arroz irrigado no sul do Brasil. Brasília: Embrapa Informação Tecnológica, 2004. p.75-95.

REICHERT, J.M.; KAISER, D.R.; REINERT, D.J.; RIQUELME, U.F.B. Variação temporal de propriedades físicas do solo e crescimento radicular de feijoeiro em quatro sistemas de manejo. Pesquisa Agropecuária Brasileira, v.44, p.310-319, 2009. DOI: 10.1590/S0100-204X2009000300013.

REUNIÃO TÉCNICA ANUAL DO MILHO, 58.; REUNIÃO TÉCNICA ANUAL DO SORGO, 41., 2013, Pelotas. Indicações técnicas para o cultivo de milho e de sorgo no Rio Grande do Sul: safras 2013/14 e 2014/2015. Brasília: Embrapa, 2013. 123p.

SANTOS, H.G. dos; JACOMINE, P.K.T.; ANJOS, L.H.C. dos; OLIVEIRA, V.A. de; LUMBRERAS, J.F.; COELHO, M.R.; ALMEIDA, J.A. de; CUNHA, T.J.F.; OLIVEIRA, J.B. de. Sistema brasileiro de classificação de solos. 3.ed. rev. e ampl. Brasília: Embrapa, 2013. 353p.

SCHAEDLER, C.E.; NOLDIN, J.A.; EBERHARDT, D.S.; AGOSTINETTO, D.; BURGOS, N.R. Globe fringerush (Fimbristylis miliacea) cross resistance to als-inhibitor herbicides under field conditions in irrigated rice in the south of Brazil. Planta Daninha, v.31, p.893-902, 2013. DOI: 10.1590/ S0100-83582013000400016.

SILVA, P.R.A.; BENEZ, S.H.; JASPER, S.P.; SEKI, A.S.; MASIERO, F.C.; RIQUETTI, N.B. Semeadora-adubadora: mecanismos de corte de palha e cargas verticais aplicadas. Revista Brasileira de Engenharia Agrícola e Ambiental, v.16, p.1367-137, 2012. DOI: 10.1590/S1415-43662012001200015.

SIX, J.; BOSSUYT, H.; DEGRYZE, S.; DENEF, K. A history of research on the link between (micro)aggregates, soil biota, and soil organic matter dynamics. Soil and Tillage Research, v.79, p.7-31, 2004. DOI: 10.1016/j.still.2004.03.008.

VERNETTI JUNIOR, F. de J.; GOMES, A. da S.; SCHUCH, L.O.B. Sucessão de culturas em solos de várzea implantadas nos sistemas plantio direto e convencional. Revista Brasileira Agrociência, v.15, p.37-42, 2009. 